\title{
“ASSESSMENT OF SUICIDALITY IN A GROUP OF HIV POSITIVE INDIVIDUALS ATTENDING A TERTIARY CARE HOSPITAL PRIOR TO INITIATION OF ANTIRETROVIRAL THERAPY"
}

\author{
B. Senthil Sayinathan
}

1. Assistant Professor. Department of Psychiatry, IRT Perundurai Medical College, Perundurai, Erode

\section{CORRESPONDING AUTHOR:}

Dr. B. Senthil Sayinathan,

Assistant Professor,

Department of Psychiatry,

IRT-Perundurai Medical College,

Perundurai, Erode

E-mail: sainathansenthil@gmail.com

INTRODUCTION: Acquired Immuno Deficiency Syndrome (AIDS) is caused by Human Immuno Deficiency Virus (HIV). Infection with HIV-1 virus type can have a significant impact on immune system as well as on central nervous system. The HIV/AIDS global epidemic has greatly exceeded earlier predictions and it is now clear that it has the potential to affect all countries and all population groups. About $95 \%$ of all HIV/AIDS infected people are living in developing countries. These countries have to cope with the huge burden of suffering and death. Globally, nearly 42 million people are now living with HIV/AIDS, about one-third are in between $15 \& 24$ years of age, 3 million people are newly infected in every year, young women are especially vulnerable, most people do not know that they are infected. India accounts for $10 \%$ of global HIV burden. In India, every day 1500 people are newly infected with HIV (50\% below 25 years of age group). Currently India has an estimated prevalence of $0.23-0.33 \%$.

Prior to anti retroviral therapy (ART), viable long-term treatment options for HIV infection were unavailable and advanced HIV disease was a terminal illness. Because HIVpositive persons were acutely aware of the progressive nature of their illness, perceived risk for developing AIDS and AIDS-related life events were important determinants of suicide intent. The burden of coping with insidious onset of functional limitations related to advanced HIV disease and the ever-present threat of death may partially explain the markedly elevated suicide rate among HIV-positive persons during this period. Even though the rates of suicide decreases after the introduction of HAART, still it remains high compared to general population.

Suicide is a significant public health problem worldwide. Suicide has apparently existed for as long as human existence. Based on available data, globally suicide is believed to account for an average of 10- 15 deaths for every 100000 persons each year and for each completed suicide there are up to 20 failed suicide attempts. Over one million people commit suicide ever year the world over. Approximately $0.9 \%$ of all deaths are results from suicide. And suicide continues to be one of the three leading causes of death in young people between the ages 15 \& 24 years. Suicide is the result of a complex interaction of biological, genetic, psychological, cultural, and environmental factors. Studies indicate that the majority (up to two-thirds) of those who commit suicide have had contact with a health-care professional for various physical and emotional complaints in the month before their death. Unfortunately, many suicidal individuals may not spontaneously voice suicidal thoughts or plans of self-harm to their healthcare provider, and the majority of those at risk may never be asked about suicidality during 
clinical assessments. Suicidal ideation (having thoughts of wanting to die or killing oneself) is more common (up to six times more common than suicidal attempts and up to 100 times more common than completed suicides!).

Mental illness is most commonly encountered in people with HIV / AIDS. Physicians should routinely screen HIV positive patients for psychiatric co-morbidity and explicitly assess suicidal ideation, plan and intent. A mood disorder, especially Depression is a risk factor for suicide. And suicide is the most lethal outcome of untreated Depression. Stress of living with stigmatizing illness further increases suicidal risk. Cognitive-behavioral disengagement leads to increased substance abuse, hopelessness and pessimism which in turn increases the suicidal risk. Suicidal ideation is more likely to occur in those with a history of psychiatric illness and immediately following the diagnosis of HIV.

So assessment and management of mental disorders is an integral part of effective HIV /AIDS intervention programme.

AIM OF THE STUDY: To assess suicidality (suicidal behaviour) in a group of HIV positive patients attending a tertiary care hospital prior to initiation of anti retroviral therapy.

\section{OBJECTIVES}

1. To assess the prevalence and severity of suicidality (defined by suicidal ideation or attempts) following the diagnosis of HIV in a sample of HIV positive patients before initiation of anti retroviral therapy.

2. To study the correlation between suicidality and
a. Sociodemographic variables
b. Psychiatric morbidity
c. Hopelessness
d. Physical morbidity
e. Self perceived stigma

\section{HYPOTHESIS}

The following null hypothesis were postulated.

- There is no relationship between suicidality and sociodemographic variables.

- There is no relationship between suicidality and psychiatric morbidity.

- There is no relationship between suicidality and hopelessness.

- There is no relationship between suicidality and physical morbidity.

- There is no relationship between suicidality and self perceived stigma about HIV status.

REVIEW OF LITERATURE: HIV infection and psychiatric disorders have a complex relationship. Being HIV infected could result in psychiatric disorders as psychological consequences of infection or because of the effect of HIV virus on the brain. Disorders may vary from Anxiety disorders, Depression, Mania, Delirium, Dementia, Psychosis \& Substance use disorders.

Possibilities of increased prevalence of psychiatric disorders in HIV/AIDS may be due to:

(i) HIV infection owing to its malignant course and the associated stigma often results in emotional reactions of a serious nature among those infected. 
(ii) The HIV has direct effects on the brain that may lead to neurocognitive disturbances, psychosis or behavioural changes.

(iii) Opportunistic neurological and systemic infections and their treatment may lead to neuropsychiatric problems.

(iv) Some of the drugs used in HAART (Highly Active Anti Retroviral Therapy) are known to be associated with psychiatric side effects.

(v) Persons with severe mental illness are known to be vulnerable to HIV infection and there are special management concerns in this population (1), (2).

(vi) Substance abuse and HIV are linked in direct ways (intravenous drug use: IVDU) and in indirect ways by their influence on sexual behaviour.

(vii) Treatment adherence and course of illness have been found to be influenced by emotional factors and substance use.

The Neuropsychological phenomenon occurring during the course of HIV/AIDS can be broadly considered under neurobiological, psychobiological \& psychosocial aspects. Research has been carried out on psychological status of individuals with HIV/AIDS at its various stages(2), (3) such as at the time of HIV testing (disclosure), asymptomatic stage \& symptomatic stage of illness.

A person may react to a HIV positive test finding with a syndrome similar to PTSD (4) or may have severe distress on hearing about the HIV positive status. During asymptomatic period Adjustment disorder, Depression, Substance use disorder, Panic attacks, and Personality problems are common. During symptomatic period (5), (6) (CDC Classification System - Category B,C \& WHO Clinical Staging of HIV/AIDS - 2,3,4) Depression(7),(8) and Organic brain syndrome are common problems.

A number of studies have assessed the prevalence of psychiatric disorders (1-3),(7),(9-14) in HIV positive individuals. In a study done by Lykestos et al(10) on HIV positive patients attending medical outpatient department found that up to $54 \%$ had psychiatric disorders. King(11) et al noticed that $31 \%$ had psychiatric problems among AIDS outpatients. While in Indian scenario, Jacob(31) reported $26.1 \%$ of the HIV infected individuals having Psychiatric morbidity. Deshpande ${ }^{(12)}$ et al reported 34\% prevalence of psychiatric morbidity among medical inpatients in an Indian hospital. Falstic(13), Seth(14) also reported high prevalence of psychiatric morbidity in their research.

As most available studies had been done on western population, the WHO in 1994 implemented a cross cultural venture called "The WHO neuropsychiatric AIDS study (15),(16)". The overall prevalence of current medical disorders was higher in sero-positive compared to seronegative patients in two of five centres in the study. But studies by Atkinson et al(2) (1988), Williams et al ${ }^{17)}(1981)$ did not find any significance between HIV positive and negative groups with respect to prevalence of psychiatric morbidity.

Factors prone for the development of psychiatric disorders have been studied.

1. HIV related factors - Psychiatric disorders are more likely to occur at two high risk periods i.e., the period immediately within 6 months after disclosure of HIV positive status \& at the onset of physical complications of AIDS (Late stage-WHO stage IV of HIV related disease classification(6) $^{(6)}$ Holt et al(18), Kelly et al(19)\}

2. Sociodemographic factors - Older individuals may be at higher risk of HIV Dementia and Minor Cognitive/ Motor disorder. Substance users have poor psychological status, coping skills, social \& familial problems even prior to acquiring infections ${ }^{(89) .}$ 
3. Personality factors - Aspects of individual's personality such as sensation seeking, impulsivity and less effective coping skills leads to high risk sexual behaviour. Some studies show that persons with Antisocial Personality Disorder\& Borderline Personality Disorder are at high risk of acquiring HIV infection. (Golding et al(20), Perkin et al(21))

4. Past psychiatric history - Presence of psychiatric morbidity in the past favours emergence of psychiatric problems. Association between previous psychiatric diagnosis and present psychiatric problems in HIV positive patients has been noticed by Catalan et al(22).

5. Social Support - Inadequate social support system like lack of support from family, friends \&colleagues, social isolation leads to high prevalence of psychiatric disorders. (Kelly et al(19) 1998)

6. Life events - Loss of spouse, survivors guilt, health deterioration, loss of job and financial problems add fuel for the development of psychiatric problems in vulnerable population. (Cohen et al(23), Sherr et al(24), Fishman et al(25)).

PSYCHIATRIC DISORDERS AND HIV: Psychiatric co-morbidity in HIV ranges from minor cognitive deficits to frank psychosis. Depression \& Anxiety are prevalent diagnosis among those with HIV infection.(26),(27)

a) Acute Stress reactions: As with cancer or other life threatening illness, patients with HIV infection must adapt to set of psychological, social, medical factors as well as threat of death. They are confronted with issues like revealing their homosexuality, drug abuse to family and friends, indulging sex with partners, moving with family and friends and protecting themselves from opportunistic infections (Miller) ${ }^{(91)}$. So it is not surprising that $90 \%$ of individuals with recent diagnosis of HIV have acute stress reaction (WHO 1988).(29)

Emotional and behavioral reactions includes anger, guilt, fear, withdrawal, despair, confusion, appetite changes, sleep disturbances, suicidal ideations and hypochondriacal beliefs following the diagnosis of HIV (Miller et al,(28) Dilley et al,(8) Faulstich et al,(30) Jacob et al(31)). Acute stress reactions are particularly more common in homosexuals \& Intravenous drug abusers (Jacob \& Eapen) (31). Management should focus primarily on preventive measures such as pre-test and post-test counselling to reduce such emotional reactions.

b) Adjustment disorders: Adjustment disorders with depressed and/ or anxious mood is the commonest diagnosis encountered in HIV/AIDS (Dilley et al ${ }^{(8)}$,Rundell et al ${ }^{(9)}$, Jacob et $\mathrm{al}^{(1)}$, Schaerf et al(32)), often represent the individuals difficulty in adjusting to illness related events or social stressors (Perry et al 1984)(7). It depends upon the coping skills (Namir et al (33)), drug abuse or homosexuality leading to guilt, presence of psychiatric morbidity (Holland(34)et al), personality factors and social support system (Zich et al(35)).

Behavioural, cognitive, psychotherapeutic interventions and pharmacotherapy for treatment of depression or anxiety symptoms are to be considered in the management at this state.

\section{c) Mood disorders}

i) Depressive Disorders

Depressive Disorders are one of the commonest psychiatric disorders in HIV/AIDS patients. Depressive Disorders are twice common than general population. (Atkinson et al,(2) William et al(17)). Though rates of Depression is similar to sero-negative individuals in the initial 
part of illness, gradually increases as manifestation of disease sets in.(Lykestos et al(36) 1996). However Atkinson (2) found no relation between the stage of illness and Depression. According to Brown et al,(37) high prevalence rate of Depression (35-40\% ) reported in India among HIV positive individuals.

$10-20 \%$ sero-positive men reported Depression in due course of illness as noted by Catalan et al.,(22) Studies from India by Chandra et al(38) 1998, reported 40\% of sero-positive individuals suffered from Depression. Other Indian studies have found rates ranging from 10 40\%. (Chandra et al,(39) 2002, Krishna et al( ${ }^{(40)}$ ). Hintz ${ }^{(41)}$ noted that Depression is much more common in women than men. Perry \& Tross (7) reported that $17.3 \%$ of MDD cases in patients admitted for AIDS. $5-10 \%$ of HIV positive patients had MDD by Rabkin et al.(42) In a meta analysis by Jeffrey ciesla et al,(43) the frequency of MDD was twice common in sero-positive individuals than sero-negative individuals.

Emotional problems are among the most common symptoms in HIV patients with up to 98.6\% prevalence.(44) Depression is a prevalent co-morbidity in HIV infection as well as a recognized side effect of NRTI, Protease inhibitors and NNRTIs. It may also be the first presenting symptom in an HIV case.(45) It is essential to discriminate between normal response to a life threatening illness, clinical manifestation of HIV and Depressive episode while recognizing that all three can coexist. As in other serious medical illness, anhedonia may be the most reliable indicator of severe depression. HIV infected individuals are recognized to be at high risk of suicide in the period immediately after coming to know about sero-positive status, especially if they have a past psychiatric history(46).

Depression may result from

- Psychosocial problems related to illness.

- Human Immuno Deficiency Virus predilection for Limbic areas which control emotions that may lead to mood symptoms.

- Secondary to opportunistic infections or neoplasms.

- Anti neoplastic drugs \& Anti retroviral drugs

- Chance association.

It is important that somatic symptoms of depression (fatigue, loss of appetite, loss of weight) may also occur in AIDS stage of HIV infection. So weightage is to be given for cardinal psychological and cognitive symptoms like sad mood, decreased interest or pleasure, worthlessness, hopelessness, guilty feeling and suicidal ideation for diagnosing Depressive Disorders.

ii) Mania : Mania typically occurs as part of Bipolar mood disorders but may occur secondary to a variety of medical (cryptococcal meningitis) or pharmacological causes (Ganciclovir, Zidovudine, Steroids) (Johannessen et al, (47) Maxwell et al(48)). A few cases of hypomania or mania has also been reported by Sabhesan et al, (49) \& Venugopal et al. (50)

Although Manic episodes can occur early in the infection, it is more common in late phases of the infection often associated with cognitive deficits \& can be a presentation of HIV Dementia or associated with psychosis.

d) Anxiety disorders: Anxiety disorders may manifest throughout the course of HIV infections. Studies have reported prevalence rate of 2-30\% depending upon the stage of illness (Jacob et al, (31) Perkin DO et al (90)). Chandra et al reported 36\% anxiety Disorders in sero-positive 
individuals.(38) HIV positive women have had high prevalence of PTSD according to Martinez.(4) In PLWHA, Ramasubramaniam et al (51) noticed high prevalence of PTSD.

In India, higher rates of Anxiety \& Depression have been reported probably due to lack of awareness regarding the disease and inadequate counselling facilities (Madan et al,(52) Brown et $\left.\mathrm{al}^{(53)}\right)$. High rates also reported by William et al(17), Rundell et al,(54),Bing(95), Martinez(96) \& Kuupman(97) in their studies.

e) Acute psychosis: Prevalence of Psychosis in HIV/AIDS is between $0.1-5 \%$ (Harris et al(55)), most often found in late stages of HIV infection. The clinical picture is dominated by delusions, hallucinations and thought disorder. Psychotic symptoms can occur as a part of Delirium, Dementia, Mania and Organic brain syndrome. They are more prone for rapid deterioration of medical and cognitive symptoms (Harris(55)). Acute Psychosis may occur in the context of cognitive impairment (Rundell (54)) or may occur without evidence of cognitive impairment (Miller(28)).

Psychotic symptoms seen in HIV infected individuals may be primary or secondary(56) . Acute Psychosis in AIDS responds well to neuroleptics but extrapyramidal symptoms are much more common.

f) Delirium: Delirium denotes that CNS related problems have begun in HIV infection. Delirium may occur in relation to HIV Dementia (Price (57)), or Aseptic meningitis (cryptococcal), or Space occupying lesion of brain (CNS Lymphoma, brain abscess from Toxoplasma gondii), or hypoxia from Pneumocystis carinii pneumonia, or metabolic causes or medications (mainly tricyclic antidepressants).

Delirium develops over hours to days and has fluctuations in intensity over the course of a day. Complete recovery is often possible if not superimposed on HIV Dementia.

g) HIV Dementia: Prevalence of HIV Associated Dementia (HAD) among asymptomatic individuals estimated to be $15-30 \%$ in western population. (Heaton et al,(58) Sathishchandra et al(59)). In contrast, Indian studies showed a lower prevalence of 1-2\%. (Sathishchandra et al(59)). It affects both cortical and subcortical structures especially frontal lobe, caudate nucleus $\&$ basal ganglia (Aylward et al,(60) Navia et al(61)).

Current research indicates that cognitive impairment is uncommon in asymptomatic stage. When present, it is subtle and not associated with social or occupational impairments. (Newman et al(62)). $50-80 \%$ of AIDS patients (WHO stage IV(6) of HIV / AIDS classifications) demonstrate neurocognitive deficits (Maj(16)). Objective impairments include psychomotor slowing, forgetfulness, decreased attention \& concentration, executive skills and difficulties in motor speed. Hallmarks of early stage of Dementia are apathy, lethargy, decreased concentration, social withdrawal, muscular weakness \& paralysis of lower limbs.

American Academy of Neurology AIDS Task Force(92) introduced the term HIV -1 associated Minor Cognitive/ Motor disorder (MCMD) for those who have subtle neurocognitive difficulties, not fulfilling HAD criteria.

h) Substance use disorder: HIV and substance abuse particularly alcohol, cannabis, cocaine \& heroin are interlinked. Alcohol\& cannabis are particularly related to sexual disinhibitions, failure to use condoms \& impaired judgement regarding safe sex practices. Risky sexual behaviour is the commonest reason behind HIV transmission in India. 
$25 \%$ of India's HIV positive cases reported from Northeast India though it contributes to only $3 \%$ of national population. This is because of high prevalence of substance abuse in that region. (Mirante et al,(63) Desai et al(64)). Substance abuse has 2 fold higher risk of contracting HIV (Kumar et al(65)).

\section{i) Other AIDS related psychopathology}

- Personality Disorders - Perkin et al(21)

- Delusions - Several authors have described delusions of having contracted AIDS in patients suffering from Psychotic depression, paranoid schizophrenia or Schizoaffective disorders(66)

- Factitious AIDS (Miller)(67)

- Hypochondriacal syndrome (The worried well syndrome (28) $)$ - in which the patients are anxious about contracting the virus, though they are sero-negative $\&$ disease free, even after repeated reassurance.

HIV AND SUICIDAL BEHAVIOUR: HIV infection carries enormous emotional upheavals that leads to suicide as a natural concomitant.(68,93,94) Suicide, attempted suicide and suicidal ideation are complex issues associated with life threatening conditions like HIV infection (Kelly, $\left.1998^{(19)}\right)$. According to Linenhen,(69) suicidal ideators should not be compared with attempters or completers, as they may belong to distinct but overlapping population. So suicidality is to be considered in three broad headings here -

A.suicidal ideation,

B.suicidal attempts

C.completed suicide.

HIV can be a significant risk factor for suicide. Chronic pain, anxiety and depression should prompt a through suicidal risk assessment. Suicidal attempt is most likely to occur in those with a history of psychiatric illness and in the immediately following the diagnosis of HIV.(46)

Some of the psychiatric variables predicting suicidal ideation include concurrent substance abuse, past history of depression and presence of hopelessness. Stigma associated with HIV has been considered as an important variable in predicting suicide.

A. Suicidal ideation: Suicidal ideation refers to thoughts, fantasies, ruminations, and preoccupations about death, self-harm and self-inflicted death. Greater the magnitude and persistence of the suicidal thoughts, higher the risk for eventual suicide.

In order to determine the nature and potential lethality of the patient's suicidal thoughts, it is necessary to elicit the intensity, frequency, depth, duration and persistence of the suicidal thoughts. Even if the patient initially denies thoughts of death or suicide, the clinician should ask additional questions to find out the risk of suicidal behaviour. Asking patients how they feel about the future or how they have been making or anticipating future plans may provide useful insights. Patients who are considering suicide may be ambivalent or fatalistic about the future, may describe a future devoid of hope, may express despair about the future or may not think about the future at all.

- Prevalence Rates: Most of the studies have focused on people with AIDS (WHO stage IV of HIV/AIDS classification(6) ${ }^{(6)}$.Rabin et al(70), noted $57 \%$ of long term survivors of AIDS had 
suicidal ideation. However there are few studies that deal with HIV positive patients in initial stages. Kelly suggested that there is increased risk of suicidal ideation in symptomatic HIV positive men. Sherr et al,(24) noticed $31 \%$ prevalence rate of suicidal ideation. Carrico(71) reported suicidal ideation in $19 \%$ of the sample during the week prior to assessment. Robertson et al,(72) found that $2 / 3^{\text {rd }}$ of HIV positive individuals had suicidal ideation at some point of time while $1 / 3^{\text {rd }}$ had current suicidal ideation. Shelton et al,(73) noted that $59 \%$ of the sample were ever thinking about suicide. Various studies have found significant rates of prevalence of suicidal ideation among individuals with HIV/AIDS.(Judd,(74) Kalichman,,75) Cooperman,(76) Caroline cassel(77))

Among Indian studies, Chandra et al(38) reported $20 \%$ of the sample expressed death wishes, $12 \%$ reported occasional suicidal ideations and $6 \%$ reported persistent suicidal ideations. Another study has found suicidal ideation rates of upto $41 \%$. (Santhosh ${ }^{(78)}$ )

Risk Factors: Certain triggers precipitate suicidal ideation in HIV infected people. These include episodes of mental disorder such as Depression, Anxiety, Psychosis and Delirium. Previous research has suggested that Depressive Disorder is common among cancer patients and HIV infected patients who expressed suicidal ideation and a desire for hastened death. (Chochinov et al, 1995 (79)).

Psychiatric disorders are more likely to occur at two high risk periods i.e., the period immediately within 6 months after disclosure of HIV positive status \& at the onset of physical complications of AIDS (Late stage -WHO IV of HIV/AIDS classification) \{Holt(18), Kelly(19)\}.

Psychosocial factors like perceived stigma about the illness, social isolation, poor social support system, substance abuse, past history of Deliberate Self Harm (DSH), deviant personality traits, hopelessness are the risk factors of having suicidal ideation. In a study by Kelly et al(13) 1998, the most prevalent psychiatric diagnosis among the HIV positive individuals with suicidal ideation were Major Depressive Disorder (64\%), Drug dependence (52\%) and Depressive Personality Disorder. Kelly compared HIV positive \& HIV negative men and stated that history of alcohol use, Major Depressive Disorder, past history of suicidal attempts, personality disorder have also been associated with increased suicidal risk but he also found that there is no significant association between two groups regarding psychosocial stressors like perceived stigma, social isolation, poor social support.

Rabkin et al (70) found that highest association with current suicidal ideation in a sample of HIV positive patients was a past psychiatric history and previous suicidal attempts. Hopelessness appears to be the key factor in those contemplating suicide. (Beck(30))

A recent study on suicidal ideation in Bangalore,(78) identified demographic risk factors for suicidal ideation that included female sex, lower education level, lower monthly income level and presence of physical distress. Psychiatric variables significantly associated with suicidal ideation were similar to those found in western studies and include presence of depression, hopelessness and anxiety. An important finding of this study that has implications for policies and training was the finding that health care related stigma was highly correlated with suicidal ideation and its severity.

B. Attempted suicide: Suicidal intent refers to the patient's expectation and commitment to die by suicide. The strength of the patient's intent to die may be reflected in the patient's subjective belief in the lethality of the chosen method, which may be more relevant than the chosen method's objective lethality. Stronger the intent to die, greater the risk for completed suicide. 
Prevalence studies: Studies done on attempted suicide in HIV/AIDS individuals is characterized by methodological variations, leading to difficulty in comparing the results. Inspite of the fact that suicide attempts are more common than completed suicide, Research in this area of HIV/AIDS is scarce. In a study on long term AIDS survivors, Rabkin (70) found that 2 out of 53 men had an attempt since knowing their diagnosis of AIDS. Rundell(54) \& Brown (53) in their cohort study noticed $40 \%$ of men attempted suicide within 3 months of diagnosis of HIV. Cooperman et al (76) found that $26 \%$ of the women attempted suicide within a month of diagnosing HIV status. Shelton et al (73) noticed $50 \%$ of those individuals with HIV reported attempting suicide at some point of time.

Chandra et al (38) found that, $8 \%$ of the sample had made attempts to commit suicide.

Risk factors: Gala et al (81) found that Deliberate Self Harm to be seven times greater in those HIV positive patients with previous psychiatric problems. Catalan et al (82) noticed that depression predisposes the HIV positive persons to the risk of suicidal attempts.

Sherr et al (24) also reported that suicidal attempts were much more common with the first peak at the time of diagnosis and the second peak at the time of development of AIDS stage of HIV infection. He also reported that almost all suicidal attempts occurred within a year that too within 6 weeks of diagnosis.

C. Completed suicide Data collected mainly by retrospective assessment of death certificates \& post-mortem findings which may not be the reliable indicators of suicidal intent. Suicide rate for men with AIDS aged between 20 \& 55 years was 36 times greater than men without AIDS of the same age group. Suicide rate for men with AIDS aged between $20 \& 55$ years was 66 times more than that of general population. (Marzuk ${ }^{(68)}$ )

Dannerberg (83) in a study of death certificates documented 7.4 times higher rate of suicide in persons with AIDS than general population. SanFrancisco (84) study demonstrated that the death due to suicide accounted for $0.8 \%$ of overall deaths in AIDS patient.

From the above studies we know that the following factors are associated with increased suicidality in HIV/AIDS patients

- Significant suicidal ideation

- Specific intent or plan

- Loneliness

- Hopelessness

- Poor Social support system

- Perceived self stigma

- Previous suicide attempts

- Poor Coping strategies \& Personality factors

- Depression \& other mood disorders

- Family history of suicide or mood disorders

- Schizophrenia \& other psychotic disorders

- Organic mental syndromes

- Intoxication with alcohol \& other substances

- Current Psychosocial stressors \& Interpersonal Problems

- Physical Co morbidity 


\section{MATERIALS AND METHODS}

Setting: The sample was drawn from ART Centre situated in Thanjavur Medical College Hospital. Patients were referred from general practitioners, nearby general hospitals, primary health centres, other ART centres, Raja Mirasudhar Hospital and Thanjavur Medical College Hospital. This centre provides information and education about HIV and AIDS, giving pre-test counselling, post-test counselling, diagnosing and treating the affected individuals.

Design: A "Cross sectional study design" was used in this study.

Recruitment: Consecutive 85 patients found to be positive for their HIV status, registered at ART centre, Thanjavur Medical College Hospital, Thanjavur, from 1.04.2010 to 31.07.2010 who satisfied the inclusion criteria of this study were selected. HIV status was diagnosed as per WHO guidelines.

\section{Inclusion criteria:}

1. Age more than 18 years.

2. Confirmation of diagnosis as per WHO guidelines.

3. Awareness of diagnosis (HIV Positivity) for a minimum period of 1 week prior to research interview.

4. Those who were willing for giving consent for this study.

\section{Exclusion criteria:}

1. Patients with severe mental illness of such severity so as to preclude the interview.

2. Patients with severe physical illness of such severity so as to preclude the interview.

3. Those who were unwilling for giving consent for this study.

4. Patients with HIV/AIDS who were on Anti Retroviral Therapy.

\section{Data collection}

\section{Assessment:}

The following were employed to collect the data for this study.

1. A semi structured proforma to collect sociodemographic details and psychiatric history. (Appendix - 1)

2. ICD - 10 clinical and diagnostic criteria.

3. (HAM - D) - Hamilton Rating Scale for Depression - 17 items. (Appendix - 2)

4. BHS - Beck Hopelessness Scale (Appendix - 3)

5. SSI - (Beck) Scale for Suicidal Ideation (Appendix - 4)

6. SIS - (Beck) Suicide Intent Scale. (Appendix - 5)

\section{Semi - structured proforma}

The following information was collected.

a. Sociodemographic data - Details about Pre ART No, Time interval between knowledge of HIV status and Assessment, Age, Sex, Religion, Marital status, Education, Occupation, Region, Socio Economic status ${ }^{(98)}$ and Social Support were collected.

b. Clinical characteristics - information regarding substance use, sexual preference, current psychiatric diagnosis, personality trait, suicidality (current and past), past 
history of psychiatric morbidity, family history of suicide and psychiatric illness were collected.

c. Medical morbidity - co-existing physical illness included.

d. Perception of HIV status - a 5 point LIKERT SCALE was used to assess individual perception of stigmatizing nature of HIV infection.

\section{ICD - 10 clinical and Diagnostic criteria.}

This was used to diagnose current and past psychiatric morbidity.

3. HAM-D: Hamilton first described his Depression Rating Scale in 1960 's(99). Its intended use was to quantify the results of interview, and its value depended on the skill of the interviewer in eliciting necessary information. Many versions of HAM-D have been made, but 17 - items scale was used in this study.

Each variable has been given a score of $0-4$ and the total score is interpreted as

\begin{tabular}{|c|l|}
\hline $0-7$ & None / Minimal Depression \\
\hline $8-17$ & Mild Depression \\
\hline $18-25$ & Moderate Depression \\
\hline $26+$ & Severe Depression \\
\hline
\end{tabular}

\section{Beck Hopelessness Scale (BHS)}

It was devised by Aaron Beck, Weissman et al (1974). It consists of 20 items of thoughts or feelings about future which the subject rates true or false (self-rating scale). Half the items are keyed true and half false, with a total score of 20 for maximum hopelessness. The severity of hopelessness is reported to have a high degree of correlation with suicidal ideation.

\section{Beck Scale of Suicidal Ideation (SSI)}

It is a 21-item scale with scores ranging 0-2 on individual items (background factors V-items 20 and 21 are not included in total score). The possible range of scores is between 0 and 38. This is designed to quantify the intensity of current, conscious suicidal ideation by measuring self-destructive thoughts or wishes. It is completed by a clinician based on patient's answers in a semi-structured interview.

The scale is divided into 5 sections.

a. Characteristics of attitude towards living / dying

b. Characteristics of suicidal ideation / wish

c. Characteristics of contemplated attempt.

d. Actualization of attempt contemplated.

e. Background factors 


\section{Beck Suicide Intent Scale (SIS)}

Beck, Schuyler and Herman (1974) developed a scale to measure the degree of suicidal intent following attempted suicide. The scale has two sections.

Part I - Includes items 1 to 8

It covers the objective circumstances of the attempt and includes items on the preparation for and manner of execution of attempt, the setting and clues given before hand by the patient that could hamper or facilitate intervention or discovery.

Part II - Includes items 9 to 15

It describes the patient's expectations and feelings at the time of attempt.

The scale includes 15 items each item related on a three point score $(0,1,2)$. The total score $(0-30)$ is used to assess the intent of suicidal attempt. High scores correspond to high suicidal intent.

\begin{tabular}{|l|l|}
\hline Score & Interpretation \\
\hline $15-19$ & Low intent \\
\hline $20-28$ & Medium intent \\
\hline $29+$ & High intent \\
\hline
\end{tabular}

PROCEDURE: A total of 85 cases were recruited for the study over a period of 4 months from 14-2010 to 31-7-2010. Informed consent was obtained from each patient prior to interview. The subjects were assured of confidentiality. The study was approved by Ethical Committee of Thanjavur Medical College.

85 consecutive HIV positive patients registered at ART Centre at Thanjavur Medical College Hospital who fulfill the inclusion criteria of the study were selected.

Every patient underwent a semi-structured clinical interview, and psychiatric morbidity if present was assessed based on ICD - 10 clinical and diagnostic criteria. Other relevant informations were also obtained from their attenders, with patient's consent. Information regarding past history and medical illness was also procured. All the informations collected were then entered into the semi-structured proforma.

Past and current suicidality were assessed through interview and rating scales. Beck Scale for Suicide Ideation measured suicidal ideation during the week preceding interview and Suicide intent for the most recent suicidal attempt was assessed by Beck Suicidal Intent Scale. Current hopelessness and depression were measured by Beck Hopelessness Scale and the Hamilton Depression Rating Scale - 17 items.

DATA ANALYSIS: Descriptive statistics were computed. Bivariate analysis of Pearson's chisquare test was done to find out the differences between categorical independent variables and dependent variables.

Mean of two groups (those with current suicidal ideation and those without current suicidal ideation) were compared by using analysis of variants (ANOVA) test. Data was analysed by using the statistical passage of social science - version 12 . 


\section{RESULTS}

Sample Description: 85 HIV positive individuals prior to initiation of anti-retroviral therapy were recruited for the study.

Sociodemographic distribution:Table : 1

\begin{tabular}{|c|c|c|c|}
\hline S.No & Variable & $\mathbf{N}$ & $\%$ \\
\hline 1. & Age in years [Mean (SD)] & $33.76(7.91)$ & \\
\hline \multirow[t]{4}{*}{2.} & Sex & & \\
\hline & Male & 48 & 56.5 \\
\hline & Female & 36 & 42.4 \\
\hline & Transgender & 1 & 1.2 \\
\hline \multirow[t]{4}{*}{3.} & Religion & & \\
\hline & Hindu & 77 & 90.6 \\
\hline & Muslim & 3 & 3.5 \\
\hline & Christian & 5 & 5.9 \\
\hline \multirow[t]{5}{*}{4.} & Marital Status & & \\
\hline & Single & 10 & 11.8 \\
\hline & Married & 63 & 74.1 \\
\hline & Widowed & 6 & 7.1 \\
\hline & Divorced / Separated & 6 & 7.1 \\
\hline \multirow[t]{7}{*}{5.} & Education & & \\
\hline & Illiterate & 10 & 11.8 \\
\hline & Primary & 28 & 32.9 \\
\hline & Middle & 18 & 21.2 \\
\hline & Secondary & 13 & 15.3 \\
\hline & Higher Secondary & 6 & 7.1 \\
\hline & Degree & 10 & 11.8 \\
\hline \multirow[t]{3}{*}{6.} & Occupation & & \\
\hline & Employed & 51 & 60 \\
\hline & Unemployed & 34 & 40 \\
\hline \multirow[t]{3}{*}{7.} & Region & & \\
\hline & Urban & 25 & 29.4 \\
\hline & Rural & 60 & 70.6 \\
\hline \multirow[t]{3}{*}{8.} & Socio economic status & & \\
\hline & Middle & 14 & 16.5 \\
\hline & Lower & 71 & 83.5 \\
\hline \multirow[t]{4}{*}{9.} & Social Support & & \\
\hline & Poor & 61 & 71.8 \\
\hline & Moderate & 16 & 18.8 \\
\hline & Good & 8 & 9.4 \\
\hline 10 & $\begin{array}{l}\text { Time interval between knowledge of HIV } \\
\text { status and assessment in months }\end{array}$ & 4.71 & \\
\hline
\end{tabular}


The sample consisted of individuals between minimum of 20 years to maximum of 55 years of age with a mean age of 33.76 years. 48 individuals were male (56.5\%), 36 were female (42.4) and 1 was transgender (1.2\%).

90.6\% of the sample were Hindus. Muslims and Christians constituted 3.5\% and 5.9\% respectively. Majority of the sample population were married (74.1\%). 11.8\% of the sample were unmarried or single, $7.1 \%$ were divorced or separated and $7.1 \%$ were widowed.

$32.9 \%$ of the sample completed their primary education. The proportion of the sample who completed middle, secondary, higher secondary and degree or above level of education were $21.2 \%, 15.3 \%, 7.1 \%$ and $11.8 \%$ respectively. Illiterate people were $11.8 \%$ of the sample.

$60 \%$ of the sample were employed, remaining were unemployed (40\%). $70.6 \%$ hailed from rural background and $29.4 \%$ from urban background. Majority were from low socioeconomic status. $71.8 \%$ of the sample had poor social support system $(18.8 \%$ had moderate support and $9.4 \%$ had good support).

Time interval between knowledge of HIV status and assessment range from 1 week to 5 years. The mean duration was 4.7 months.

II Psychiatric characteristics: Table : 2

\begin{tabular}{|c|c|c|c|}
\hline S.No & Variable & $\mathbf{N}$ & $\%$ \\
\hline \multirow[t]{10}{*}{1.} & Current Psychiatric diagnosis & & \\
\hline & 1. Absent & 47 & 55.3 \\
\hline & 2. Present & 38 & 44.7 \\
\hline & - Depressive disorder & 12 & 14.1 \\
\hline & - Adjustment disorder & 14 & 16.5 \\
\hline & - Anxiety disorder & 1 & 1.2 \\
\hline & - Phobic anxiety disorder + Depression & 1 & 1.2 \\
\hline & - Alcohol dependence & 5 & 5.9 \\
\hline & - Alcohol harmful use & 4 & 4.7 \\
\hline & - Mental retardation & 1 & 1.2 \\
\hline \multirow[t]{5}{*}{2.} & Deviant personality trait & & \\
\hline & 1. Absent & 83 & 97.6 \\
\hline & 2. Present & 2 & 2.4 \\
\hline & - Borderline personality & 1 & 1.2 \\
\hline & - Anti social personality & 1 & 1.2 \\
\hline \multirow[t]{6}{*}{3.} & Past psychiatric morbidity & & \\
\hline & 1. Absent & 77 & 90.6 \\
\hline & 2. Present & 8 & 9.4 \\
\hline & - Alcohol dependence & 4 & 4.7 \\
\hline & - Alcohol harmful use & 3 & 3.5 \\
\hline & - Anxiety disorder & 1 & 1.2 \\
\hline \multirow[t]{3}{*}{4.} & Sexual preference & & \\
\hline & 1. Heterosexual & 81 & 95.3 \\
\hline & 2. Homosexual & 1 & 1.2 \\
\hline
\end{tabular}




\begin{tabular}{|c|l|c|c|}
\hline \hline \multicolumn{1}{|l|}{ 3. Bisexual } & 3 & 3.5 \\
\hline $\mathbf{5 .}$ & $\begin{array}{l}\text { Family history of } \\
\text { Psychiatric morbidity }\end{array}$ & & \\
\hline & 1. Absent & 72 & 84.7 \\
\hline & 2. Present & 13 & 15.3 \\
\hline $\mathbf{6 .}$ & Family history of suicide & & \\
\hline & 1. Absent & 71 & 83.5 \\
\hline & 2. Present & 14 & 16.5 \\
\hline
\end{tabular}

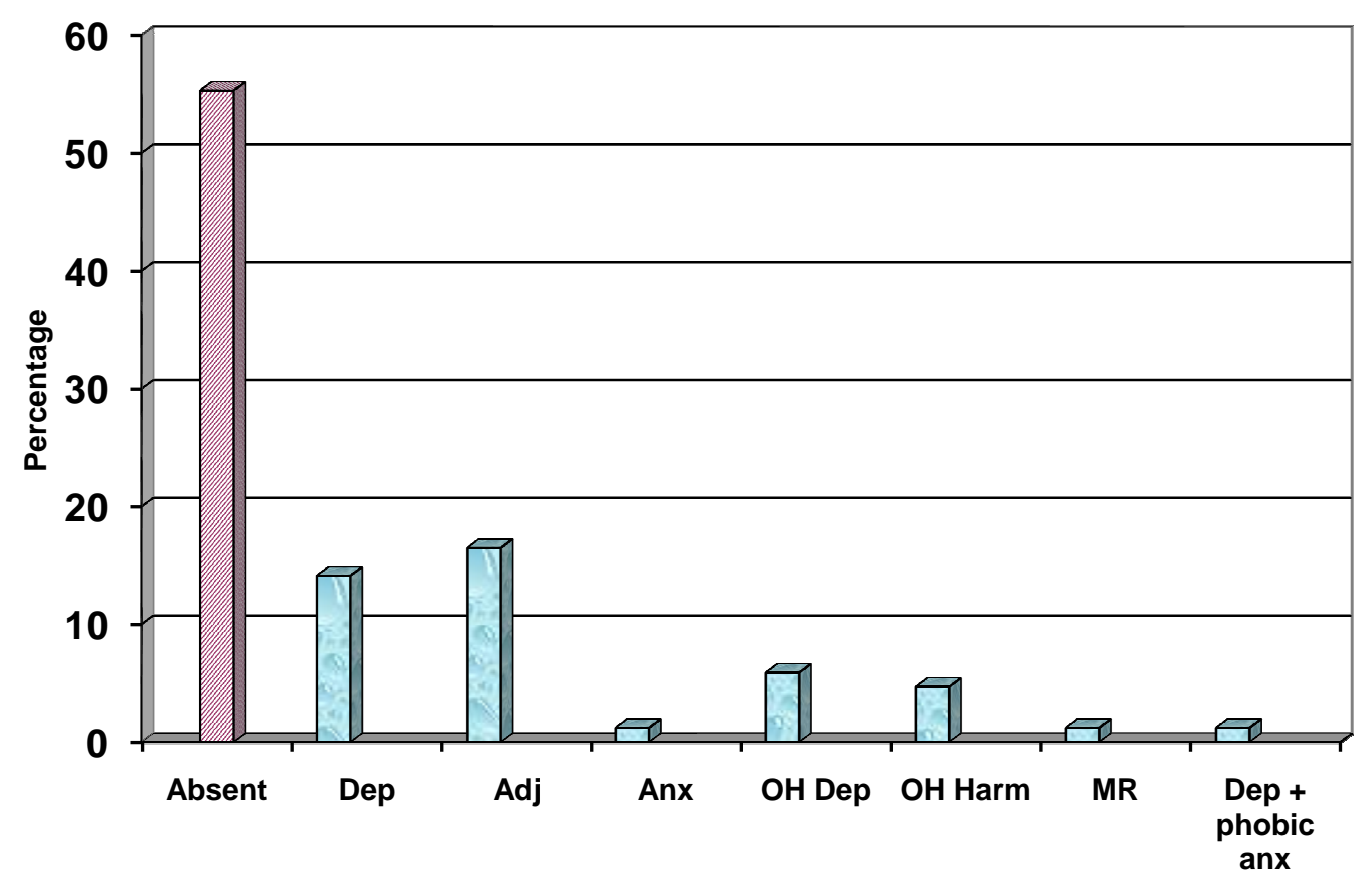

Current Psy. diagnosis

Psychiatric diagnosis based on ICD -10 criteria was present in $44.7 \%$ of the sample, Adjustment disorder with mixed anxiety and depressive reaction being the commonest (16.5\%) followed by Depressive disorder (14.1\%). Alcohol dependence and Alcohol harmful use constituted 5.9\% and $4.7 \%$ respectively. Other diagnoses were mental retardation (1.2\%) and Anxiety disorder (1.2\%). 1 patient (1.2\%) had phobic anxiety disorder (Blood or injury type) with co-morbid Depression.

HAM-D score varies from 0 to 27 with mean (S.D) value of 7.2.

8 out of 85 patients had past history psychiatric morbidity of which 4 patients had Alcohol dependence and 3 patients had Alcohol harmful use and 1 patients had Anxiety disorder. 
2 persons $(2.4 \%)$ had deviant personality trait of which 1 person had Antisocial Personality Disorder (1.2\%) and one had Borderline Personality Disorder (1.2\%)

$95.3 \%$ were heterosexual 3.5\% were bisexual and 1.2\% (1 person) was homosexual in their sexual preference.

Family history of psychiatric morbidity was present in $15.3 \%$ of the sample and family history of suicide was present in $16.5 \%$ of the sample.

III Suicidality Table: 3

\begin{tabular}{|c|l|c|c|}
\hline S.No & \multicolumn{1}{|c|}{ Variable } & N & \% \\
\hline 1. & $\begin{array}{l}\text { Suicidal ideation any time following } \\
\text { diagnosis of HIV. }\end{array}$ & & \\
\hline & \multicolumn{1}{|c|}{ Yes } & 33 & 38.8 \\
\hline & \multicolumn{1}{|c|}{ No } & 52 & 61.2 \\
\hline 2. & Current suicidal ideation & 63 & 74.1 \\
\hline & \multicolumn{1}{|c|}{ Absent Present } & 22 & 25.9 \\
\hline 3. & $\begin{array}{l}|c| \\
\text { Previous attempts after } \\
\text { HIV Diagnosis }\end{array}$ & 2 & 2.4 \\
\hline & HAM - D [Mean (S.D)] & \multicolumn{2}{|c|}{4.11} \\
\hline & Scale for suicidal Ideation (SSI) & \multicolumn{2}{|c|}{3.95} \\
\hline & Suicidal Intent Scale (SIS) & & \\
\hline & BHS & & \\
\hline
\end{tabular}

Individuals were assessed for current and past suicidality.

Suicidal ideation: Out of the 85 HIV positive patients, 33 (38.8\%) had suicidal ideation at some point of time following the diagnosis of HIV. 22 persons $(25.9 \%)$ had current suicidal ideation. The scores for suicidal ideation (SSI) varied from 0 to 30 . The mean score was 4.11 .

Suicidal attempts: 6 out of 85 patients i.e 7.1\% had history of suicidal attempts. The score for suicidal intent varied from a minimum of 12 to maximum score of 18 with mean score of 15.3. Among the 6 persons, $2(2.4 \%)$ patients had attempted suicide following notification of HIV status within 6 months of diagnosis.

IV HopelessnessThe Beck Hopelessness score varied from 0 to 19 with a mean value of 3.95 .

V Medical Morbidity36 patients (42.4\%) had physical morbidity at the time of assessment. Physical morbidity was present in 36 patients as given below.

Table 4:

\begin{tabular}{|l|c|c|}
\hline Diagnosis & $\mathbf{N = 3 6}$ & $\mathbf{\%}$ \\
\hline a. Oral manifestations & 7 & 19.4 \\
\hline b. Dermatological & 4 & 11.1 \\
\hline c. Gastro intestinal & 8 & 22.2 \\
\hline
\end{tabular}


ORIGINAL ARTICLE

\begin{tabular}{|l|c|c|}
\hline d. Genital & 3 & 8.3 \\
\hline e. Respiratory & 8 & 22.2 \\
\hline f. Primary infertility & 3 & 8.3 \\
\hline g. Seizure disorder & 1 & 2.8 \\
\hline h. Others & 2 & 5.6 \\
\hline
\end{tabular}

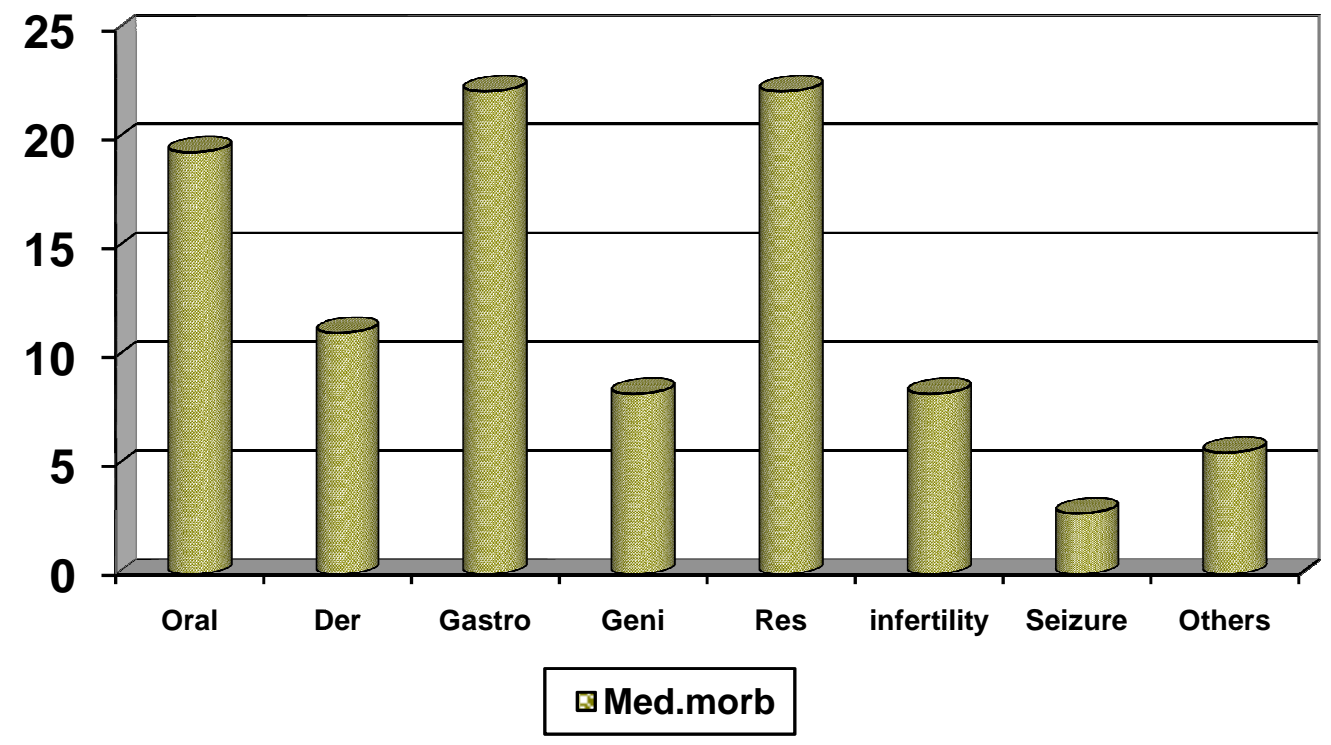

\section{Perception of HIV stigma}

$78.8 \%$ of the group felt that HIV was a stigmatizing illness $(60 \%$ agree and $18.8 \%$ strongly agree)

14 patients $(16.5 \%)$ did not know about stigma associated with HIV illness while 4 patients $(4.7 \%)$ disagreed.

Table -5

PERCEPTION OF HIV STATUS

\begin{tabular}{|c|c|c|c|c|c|}
\hline & & Frequency & Percent & Velid Percent & $\begin{array}{l}\text { Surr ulative } \\
\text { Percent }\end{array}$ \\
\hline \multirow[t]{5}{*}{ Valic } & STRDNGL $Y$ AGREE & 16 & 18.8 & 18.8 & 188 \\
\hline & AGPEE & 51 & 600 & 60.0 & 788 \\
\hline & DONTKNOW & 14 & 15.5 & 16.5 & 953 \\
\hline & USAGREt & 4 & 4.7 & $<.7$ & 1000 \\
\hline & otal & 85 & 1000 & 100.0 & \\
\hline
\end{tabular}




\section{Perception of HIV stigma}

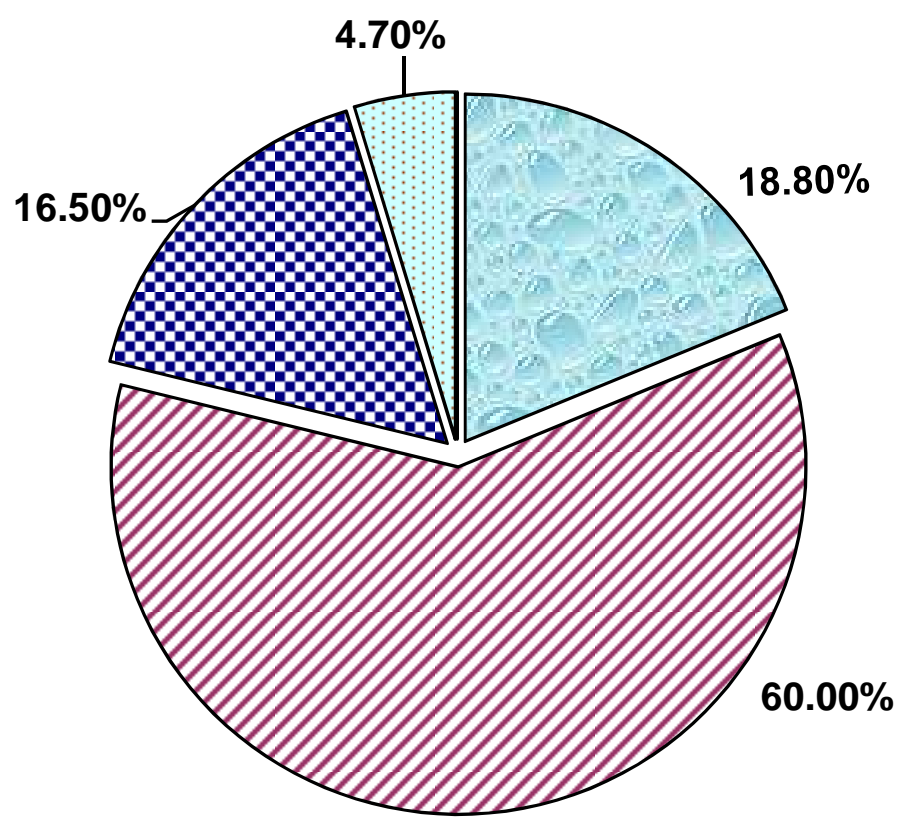

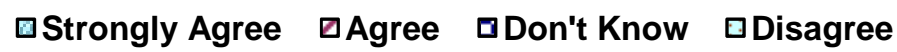

COMPARATIVE DATA :The group was divided into those with current suicidal ideation and those without current suicidal ideation. The two groups were then compared for the following variables.
a. Sociodemographic variables.
b. Psychiatric morbidity
c. Medical morbidity
d. Perception of stigma
e. Scores on HAM-D, SSI,BHS and SIS

A. Sociodemographic Variable - Table 6

\begin{tabular}{|c|c|c|c|}
\hline \multirow{2}{*}{ Variable } & \multicolumn{2}{|c|}{ Suicidal ideation } & \multirow{2}{*}{ "P" value } \\
\hline & No $(N=63)$ & Yes $(N=22)$ & \\
\hline Age in years [Mean (S.D)] & $33.46(8.22)$ & $34.6(7.06)$ & 0.552 \\
\hline \multicolumn{3}{|l|}{ Sex } & \multirow{4}{*}{0.647} \\
\hline Male & $34(54 \%)$ & $14(63.6 \%)$ & \\
\hline Female & $28(44.4 \%)$ & $8(36.4 \%)$ & \\
\hline Transgender & $1(1.6 \%)$ & & \\
\hline \multicolumn{3}{|l|}{ Religion } & \multirow{3}{*}{0.915} \\
\hline Hindu & $57(90.5 \%)$ & $20(90.9 \%)$ & \\
\hline Muslim & $2(3.2 \%)$ & $1(4.5 \%)$ & \\
\hline
\end{tabular}


ORIGINAL ARTICLE

\begin{tabular}{|c|c|c|c|}
\hline Christian & $4(6.3 \%)$ & $1(4.5 \%)$ & \\
\hline \multicolumn{3}{|l|}{ Marital status } & \multirow{5}{*}{0.111} \\
\hline Single & $5(7.9 \%)$ & $5(22.7 \%)$ & \\
\hline Married & $50(79.4 \%)$ & $13(59.1 \%)$ & \\
\hline Widowed & $5(7.9 \%)$ & $1(4.5 \%)$ & \\
\hline Divorced / Separated & $3(4.8 \%)$ & $3(13.6 \%)$ & \\
\hline Education & & & \multirow{7}{*}{0.514} \\
\hline Illiterate & $5(7.9 \%)$ & $5(22.7 \%)$ & \\
\hline Primary & $21(33.3 \%)$ & $7(31.8 \%)$ & \\
\hline Middle & $15(23.8 \%)$ & $3(13.6 \%)$ & \\
\hline Secondary & $10(15.9 \%)$ & $3(13.6 \%)$ & \\
\hline Higher Secondary & $4(6.3 \%)$ & $2(9.1 \%)$ & \\
\hline Degree & $8(12.7 \%)$ & $2(9.1 \%)$ & \\
\hline \multicolumn{3}{|l|}{ Occupation } & \multirow{3}{*}{0.686} \\
\hline Employed & $37(58.7 \%)$ & $14(63.6 \%)$ & \\
\hline Unemployed & $26(41.3 \%)$ & $8(36.4 \%)$ & \\
\hline \multicolumn{3}{|l|}{ Region } & \multirow{3}{*}{0.424} \\
\hline Urban & $20(31.7 \%)$ & $5(22.7 \%)$ & \\
\hline Rural & $43(68.3 \%)$ & $17(77.3 \%)$ & \\
\hline \multicolumn{3}{|l|}{ Socio economic status } & \multirow{3}{*}{0.802} \\
\hline Middle & $10(15.9 \%)$ & $4(18.2 \%)$ & \\
\hline Lower & $53(84.1 \%)$ & $18(81.8 \%)$ & \\
\hline \multicolumn{3}{|l|}{ Social Support } & \multirow{4}{*}{0.210} \\
\hline Poor & $42(66.7 \%)$ & $19(86.4 \%)$ & \\
\hline Moderate & $14(22.2 \%)$ & $2(9.1 \%)$ & \\
\hline Good & $7(11.1 \%)$ & $1(4.5 \%)$ & \\
\hline $\begin{array}{l}\text { Time interval between } \\
\text { knowledge of HIV status } \\
\text { and assessment (in months) }\end{array}$ & $6.06(14.05)$ & $0.86(1.22)$ & 0.088 \\
\hline
\end{tabular}

The sociodemographic distribution for the two groups is given in table 6. Both groups were compared regarding sociodemographic data. Statistically, there is no relationship between suicidality and sociodemographic variables.

\section{B. Psychiatric Characteristics - Table: 7}

\begin{tabular}{|l|l|l|l|}
\hline \multirow{2}{*}{ Variable } & \multicolumn{2}{c|}{ Suicidal ideation } & \multirow{2}{*}{ "P" value } \\
\cline { 2 - 3 } & \multicolumn{1}{|c|}{ Yes (N = 22) } & \multicolumn{1}{|c|}{ No (N = 63) } & \\
\hline $\begin{array}{l}\text { Current Psychiatric diagnosis } \\
\text { Absent } \\
\text { Present }\end{array}$ & $\begin{array}{l}4(18.2 \%) \\
18(81.8 \%)\end{array}$ & $\begin{array}{l}43(68.3 \%) \\
20(31.7 \%)\end{array}$ & 0.000 \\
\hline $\begin{array}{l}\text { 1. Depressive disorder } \\
\text { 2. Adjustment disorder }\end{array}$ & $10(55.6 \%)$ & $2(10 \%)$ & \\
3. Anxiety disorder & $7(38.9 \%)$ & $7(35 \%)$ & 0.000 \\
4. Phobic anxiety disorder + & $1(5.6 \%)$ & $1(5 \%)$ & \\
\hline
\end{tabular}




\section{ORIGINAL ARTICLE}

\begin{tabular}{|c|c|c|c|}
\hline $\begin{array}{ll}\text { 5. } & \text { Alcohression } \\
\text { 6. Alcohol harmful use } \\
\text { 7. } \\
\text { Mental retardation }\end{array}$ & & $\begin{array}{l}5(25 \%) \\
4(20 \%) \\
1(5 \%)\end{array}$ & \\
\hline $\begin{array}{l}\text { Deviant Personality trait } \\
\text { a) Absent } \\
\text { b) Present }\end{array}$ & $\begin{array}{l}21(95.5 \%) \\
1(4.5 \%)\end{array}$ & $\begin{array}{l}62(98.4 \%) \\
1(1.6 \%)\end{array}$ & 0.431 \\
\hline $\begin{array}{l}\text { Sexual preference } \\
\text { 1) } \text { Heterosexual } \\
\text { 2) Homosexual } \\
\text { 3) } \text { Bisexual }\end{array}$ & $\begin{array}{l}21(95.5 \%) \\
- \\
1(4.5 \%)\end{array}$ & $\begin{array}{l}60(95.2 \%) \\
1(1.6 \%) \\
2(3.2 \%)\end{array}$ & 0.804 \\
\hline $\begin{array}{l}\text { Past Psychiatric morbidity } \\
\text { a) Absent } \\
\text { b) Present }\end{array}$ & $\begin{array}{c}21(95.5 \%) \\
1(4.5 \%)\end{array}$ & $\begin{array}{c}56(88.9 \%) \\
7(11.1 \%)\end{array}$ & 0.364 \\
\hline $\begin{array}{c}\text { Previous attempts } \\
\text { Absent } \\
\text { Present } \\
\end{array}$ & $\begin{array}{c}19(6.4 \%) \\
3(13.6 \%) \\
\end{array}$ & $\begin{array}{l}60(95.2 \%) \\
3(4.8 \%) \\
\end{array}$ & 0.162 \\
\hline $\begin{array}{c}\text { Reason for a attempt } \\
\text { HIV Status } \\
\text { Others }\end{array}$ & $\begin{array}{l}1(33.3 \%) \\
2(66.7 \%)\end{array}$ & $\begin{array}{l}1(33.3 \%) \\
2(66.7 \%)\end{array}$ & 1.000 \\
\hline $\begin{array}{l}\text { Family history of Psychiatric } \\
\text { morbidity } \\
\text { a) Absent } \\
\text { b) Present }\end{array}$ & $\begin{array}{c}19(86.4 \%) \\
3(13.6 \%)\end{array}$ & $\begin{array}{l}53(84.1 \%) \\
10(15.9 \%)\end{array}$ & 0.802 \\
\hline $\begin{array}{c}\text { Family history of suicide } \\
\text { Absent } \\
\text { Present }\end{array}$ & $\begin{array}{c}17(77.3 \%) \\
5(22.7 \%)\end{array}$ & $\begin{array}{c}54(85.7 \%) \\
9(14.3 \%) \\
\end{array}$ & 0.358 \\
\hline
\end{tabular}

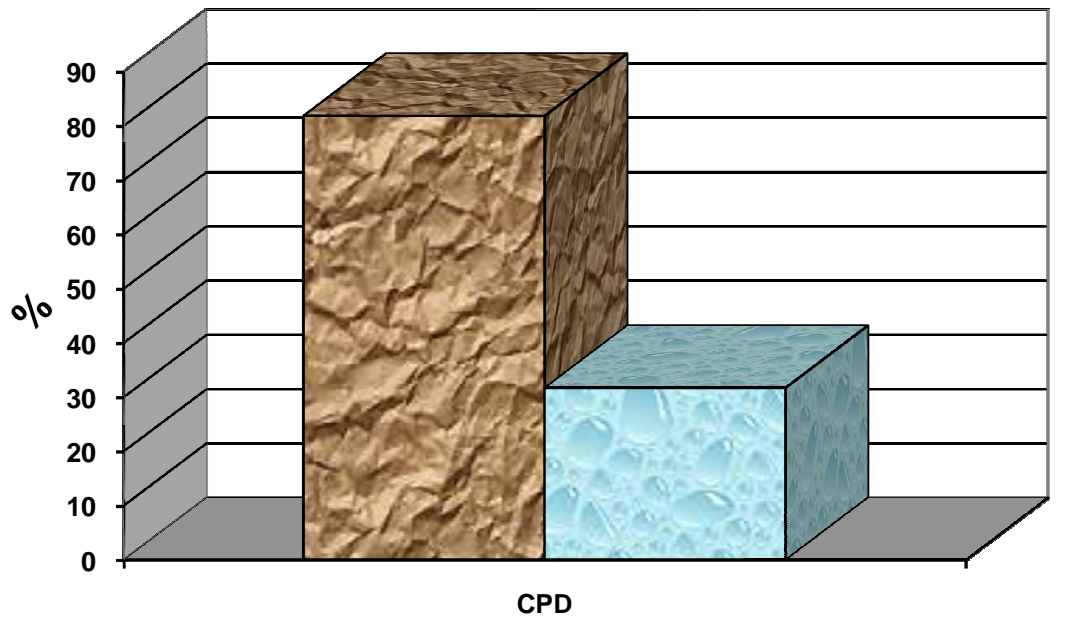

口SI 口Without SI 
Table 7 shows psychiatric characteristics for the two groups. There was a significant difference between those with and without current suicidal ideation with regard to presence of a current psychiatric diagnosis $(\mathrm{P}=0.000)$.

From the table, it is evident that there is a strong association between current suicidality and presence of psychiatric morbidity, especially Depression.

C. Medical Morbidity Table : 8

\begin{tabular}{|c|c|c|c|}
\hline \multirow{2}{*}{ Variable } & \multicolumn{2}{|c|}{ Suicidal ideation } & \multirow{2}{*}{ "P" value } \\
\hline & Yes $(\mathrm{N}=22)$ & No $(\mathrm{N}=63)$ & \\
\hline Absent & $9(40.9 \%)$ & $40(63.5 \%)$ & \multirow{2}{*}{0.065} \\
\hline Present & $13(59.1 \%)$ & $23(36.5 \%)$ & \\
\hline Oral & $2(15.4 \%)$ & $5(21.7 \%)$ & \multirow{8}{*}{0.842} \\
\hline Dermatological & $1(7.7 \%)$ & $3(13 \%)$ & \\
\hline Gastro intestinal & $4(30.8 \%)$ & $4(17.4 \%)$ & \\
\hline Genital & $2(15.4 \%)$ & $1(4.3 \%)$ & \\
\hline Respiratory & $2(15.4 \%)$ & $6(26.1 \%)$ & \\
\hline Primary infertility & $1(7.7 \%)$ & $2(8.7 \%)$ & \\
\hline Seizure disorder & 0 & $1(4.3 \%)$ & \\
\hline Others & $1(7.7 \%)$ & $1(4.3 \%)$ & \\
\hline
\end{tabular}

From the table 8 it is evident that Medical morbidity appeared to have a correlation with suicidality, but it is not significant statistically.

\section{E. Perception of Stigma Table : 9}

\begin{tabular}{|l|l|l|l|}
\hline \multirow{2}{*}{ Variable } & \multicolumn{2}{c|}{ Suicidal ideation } & \multirow{2}{*}{ “P” value } \\
\cline { 2 - 3 } & \multicolumn{1}{|c|}{ Yes (N = 22) } & No (N = 63) & \\
\hline Strongly agree & $10(45.5 \%)$ & $6(9.5 \%)$ & \multirow{2}{*}{0.001} \\
\hline Agree & $12(54.5 \%)$ & $39(61.9 \%)$ & \\
\hline Don't know & 0 & $14(22.2 \%)$ & \\
\hline Disagree & 0 & $4(6.3 \%)$ & \\
\hline Strongly disagree & 0 & 0 & \\
\hline
\end{tabular}

The perception of stigma in those with and without suicidal ideation was given in table 9. There was a significant difference between the groups with regard to self-perceived stigma related to a positive HIV status. Almost all the individuals who had current suicidal ideation agreed/strongly agreed to the stigmatizing nature of the illness. There is strong association noted between current suicidality and self perceived stigma of HIV infection. 


\section{F. Scores on Assessment Scales Table : 10}

\begin{tabular}{|l|l|l|c|}
\hline \multirow{2}{*}{ Variable } & \multicolumn{2}{c|}{ Suicidal ideation Mean (S.D) } & \multirow{2}{*}{ “P” value } \\
\cline { 2 - 3 } & Yes (N = 22) & No (N = 63) & \\
\hline HAM - D & $15.68(7.27)$ & $4.25(3.8)$ & 0.000 \\
\hline SSI & $14.5(6.8)$ & $0.49(1.22)$ & 0.000 \\
\hline BHS & $10.81(4.77)$ & $1.55(2.47)$ & 0.000 \\
\hline SIS & $16(2.0)$ & $14.6(2.3)$ & 0.492 \\
\hline
\end{tabular}

There is a strong association between current sucidality and higher scores on HAM-D, SSI and BHS.

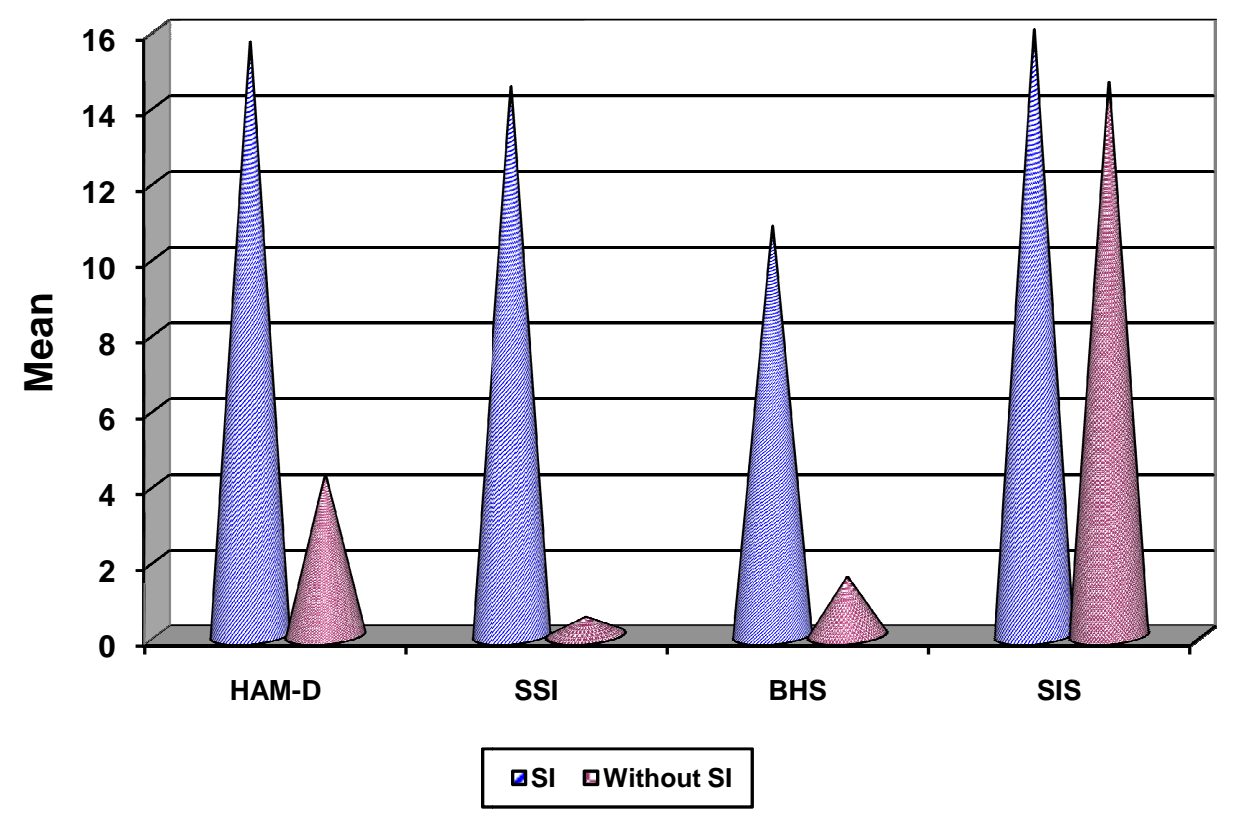

Table -11 Mean of the two groups (those with current suicidal ideation and without suicidal ideation) were compared by using analysis of variance (ANOVA). From this table it is evident that there is a strong correlation between sucidality and HAM-D, BHS, SSI scores. 


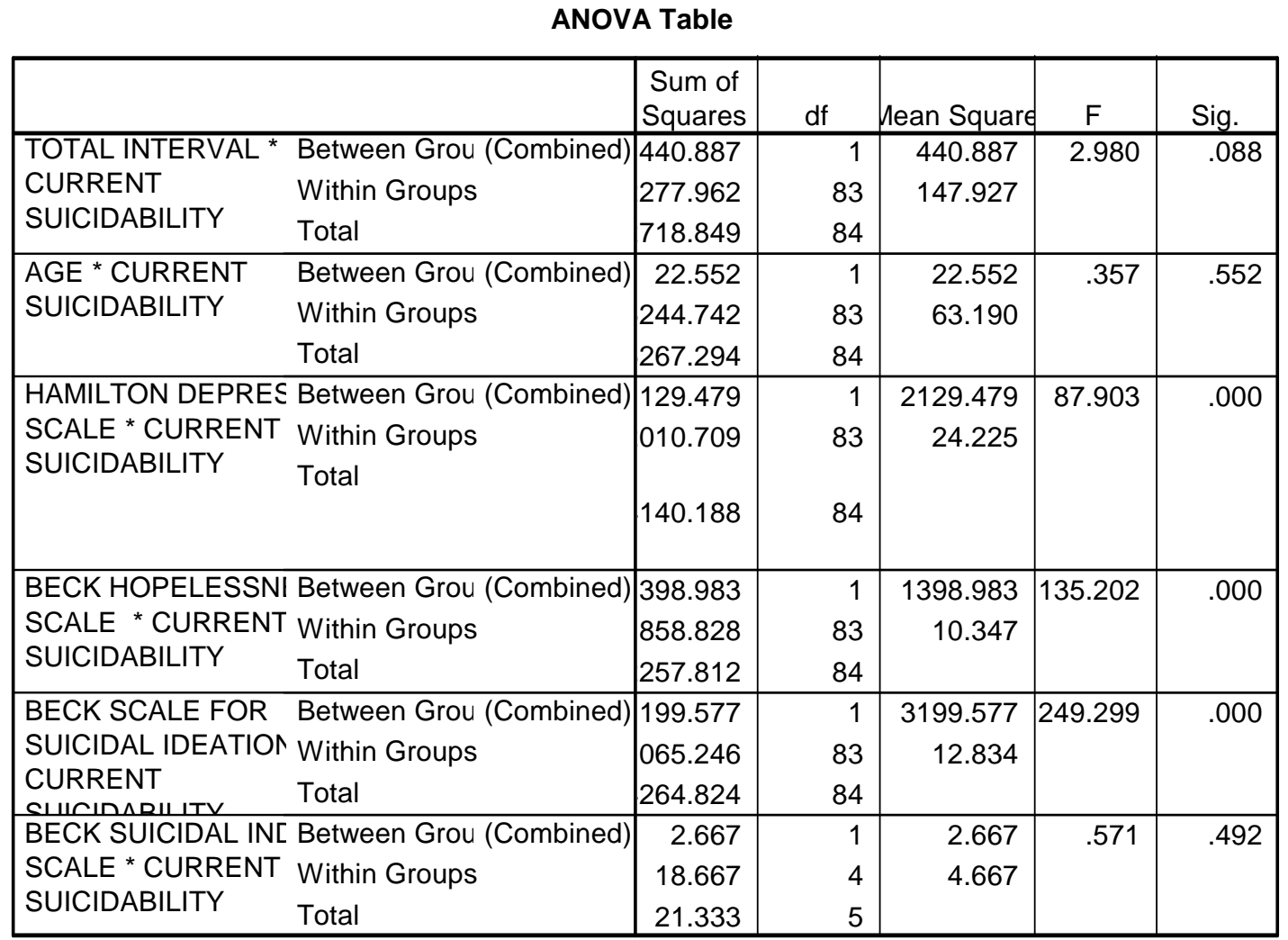

DISCUSSION : It was a cross sectional study, carried out on HIV positive patients attending ART centre at Thanjavur Medical College Hospital and Suicidality was assessed ( defined by suicidal ideation or attempt ).

SOCIODEMOGRAPHIC VARIABLES : Most of the studies on HIV / AIDS patients have focused on specific groups like Homosexual men (19,85), AIDS patients (70),Female population (76), and Intra venous drug abusers $(63,64)$. This study was done on HIV positive patients (including both males and females) prior to initiation of Anti retroviral therapy, who met the inclusion criteria for the study.

Men were more than women, may be due to men utilizing health services more than women and women were reluctant to give consent than men, 1 patient (1.2\%) was transgender in this study. The mean age of the group was 33.76 years, indicating a prevalence of HIV infection among younger age group. In study by Kelly et al (86), the mean age group was 33 years which is in concordance with this study.

Majority were Hindus and married. A proportion of unmarried, widowed, separated or divorced group constituted a considerable number than general population (25.9\%)

Most of the patients were from low socio economic status. Majority ( $>65 \%$ ) didn't complete their middle school of education. In this group $95.3 \%$ of the population was heterosexual; $1.2 \%$ was homosexual and 3.5\% was bisexual. But in western countries there was a higher proportion of homosexuals and bisexuals (87). 
CLINICAL CHARACTERS: Prevalence of psychiatric morbidity was $55.3 \%$ in this study and is similar to that of the study by Lykestos(10) et al on HIV positive patients attending medical outpatient department.(54\% deducted ).

This is higher than the prevalence rates found in studies on medical inpatients in India by Deshpande(12) et al (34\%) suggesting that HIV illness may be associated with higher psychiatric morbidity than medical illness. Jacob et al (31) reported $26.1 \%$ prevalence of psychiatric morbidity. Ahuja et al(88) also noticed a higher prevalence of psychiatric disorders as compared to the general population. Among patients with psychiatric morbidity the most common diagnosis was Adjustment disorder (16.5\%) similar to the studies by Dilley(8), Rundell(9), Schaerf(32) Jacob(31)

The second most common diagnosis in this study was Depressive Disorder (14.1\%), this is similar to the findings by Perry et al(7). The prevalence rate of 5-10\% of MDD in HIV positive patients was noticed by Rabkin et al(42). Rates of depression range from $5-25 \%$ was also noticed by Chandra et al(38), Perkins et al(21) . Chandra(38) noticed that $20 \%$ expressed death wishes, $12 \%$ reported occasional suicidal ideations, and $6 \%$ reported persistent suicidal ideations whereas $8 \%$ had made attempts to commit suicide. 10 - 40\% of HIV sero-positive individuals in Indian studies had developed Depressive Disorder, noted by Chandra et al ${ }^{(39)}$ \& Krishna et al(40).

Alcohol dependence was noticed in 4 Patients in this study (Alcohol harmful use was noted in 3 patients) whereas Lykestos et al(10) noticed $22 \%$ of HIV positive patients attending a medical out patient clinic had Alcohol dependence. Alcohol was the only substance of abuse noted in this study.

One patient (1.2\%) in this study had Anxiety disorder, $1.2 \%$ had dual diagnosis of Phobic Anxiety disorder (Blood or injury type) with co-morbid Depression, $1.2 \%$ of the sample found to be Mentally Retarded. Perkins et al(15), Kelly et al (86) found a high prevalence of Personality disorder in their studies on HIV positive patients. In this study 2 patients $(2.4 \%)$ had Deviant personality trait $(1.2 \%$ - Borderline Personality Disorder \& $1.2 \%$ - Antisocial Personality Disorder).

PREVALENCE AND SEVERITY OF SUICIDALITY: Prevalence of current suicidal ideation assessed by clinical interview and Beck Scale for Suicidal Ideation was $25.9 \%$ in this study. A total of $38.8 \%$ of the sample had Suicidal Ideation at some point of time after diagnosis of HIV. Rabkin et al(70) noted in his study that $57 \%$ of long term AIDS survivors had suicidal ideation.

The rate of current suicidality (25.9\%) is matched with findings by Perry et al(7) who found $27 \%$ of group of HIV positive individuals had suicidal ideation 1 week after information of HIV status which gradually decreases over time. Carrico et al ${ }^{(71)}$ reported, $20 \%$ of his sample had thoughts of suicide. $59 \%$ of the sample reported ever thinking about suicide in a study by Shelton(73).

$7.1 \%$ had a past history of suicidal attempts, $2.4 \%$ had attempted suicide after diagnosis of HIV infection. This findings correlates with findings of Rabkin et al(70) (2 suicide attempts among 53 long term AIDS survivors i.e after the knowledge of HIV).

Kelly et al(19) in their cross sectional study found that suicide attempt rates from 20 $29 \%$ in homosexual and bisexual man. This cannot be compared to our study which consisted of both male, female population and majority were heterosexual. 
2 out of 85 patients had attempted suicide within six moths of the diagnosis of HIV positivity. This finding is in concordance with Rundell et al(54) who reported attempted suicide within one year of post-notification period in $66.7 \%$ of his sample. In a study by Cooperman(76) $26 \%$ of women reported attempting suicide within one month of diagnosis.

CORRELATES OF SUICIDALITY: A total of 85 patients were divided into those with and without current suicidal ideation in order to assess the possible correlation with suicidality. No variation between the 2 groups during comparison of sociodemographic variables.

It was found that the risk of suicidal ideation was more common in patients with current psychiatric diagnosis compared to those without current psychiatric diagnosis, the association being strongest for Depressive Disorder (5 times more common).

Chochinor et al(79) reported Depressive Disorder to be common in HIV infected persons who expressed suicidal ideation. High correlation detected by Pearson's correlation coefficient between HAM-D, Scale for Suicidal Ideation, Beck Hopelessness Scale and current suicidal ideation $(\mathrm{P}=0.000)$. Beck et $\mathrm{al}^{(80)}$, Catalan(22) reported highest correlation between hopelessness and suicidal ideation.

According to Kelly et al(19) the risk of suicidal ideation was nearly 11 times more in individuals who had a hopelessness score $>8$, in this study mean score for hopelessness was > 10 in the group with suicidal ideation.

In our study all individuals who had suicidal ideation, agreed / strongly agreed the stigmatizing nature HIV infection. Sherr et al(24) and Rundell et al( ${ }^{(9)}$ carried out studies on social isolation and perception of self on HIV patients, confirmed the stigmatizing nature of illness. No correlation noted between family history of suicide and current suicidal ideation in this study but Kelly et al(19) noted strong correlation between suicidal behaviour in the HIV positive patients and past psychiatric history \& past or family history of suicidal attempts.

4 out of 6 patients, who attempted suicide, had history of suicide attempts prior to HIV diagnosis. It rises the possibility that suicidality that may be an inherent tendency, which may be uncovered rather than caused by stress.

Time duration after diagnosis did not appear to correlate with suicidal ideation. But Sherr et al(24) found bimodal distribution of suicidal behaviour following the diagnosis of HIV.

In our study we have noticed that, suicidal behaviour is an important area to be dealt with in HIV positive individuals. Strong association was found between suicidal behaviour and factors such as current psychiatric diagnosis, especially Depression, hopelessness and self perceived stigmatizing nature of HIV illness.

SUMMARY AND CONCLUSION: The prevalence, severity and correlates of suicidal behaviour among HIV positive patients attending a tertiary care hospital prior to initiation of Antiretroviral therapy were studied by cross sectional study design.

Suicidality was assessed on the dimensions of history, current ideations and behaviour and quantified by using Beck scale for Suicidal Ideation and Beck Suicidal Intent Scale.

To investigate the possible causes for suicidality, psychiatric status was determined by history, semi - structured clinical interview. Depression and hopelessness were quantified on Hamilton Depression Rating Scale and Beck Hopelessness Scale respectively. Self perceived stigma associated with HIV illness was assessed on 5 point LIKERT Scale. Social demographic variables, medical morbidity were also included in this study. 
Majority of the sample were young, married adults, heterosexuals and from low socioeconomic status.

$44.7 \%$ of the sample had psychiatric morbidity at the time of assessment, the most common being Adjustment Disorder (16.5\%) followed by Depression (14.1\%). Mean score for HAM-D, BHS were 7.2, 3.95 respectively. Nearly $40 \%$ had associated medical morbidity and all reported self perceived stigma associated with illness.

Current suicidality was present in $25.9 \%$ of the sample. $38.8 \%$ of the sample had suicidal ideation at some point following diagnosis of HIV. $7.1 \%$ had history of attempted suicide, 4 had (4.7\%) attempted suicide even before notification of HIV status. Suicide attempts following diagnosis of HIV had taken place within 6 months. Mean score for suicidal ideation was 4.11. Mean score for suicidal intent was 15.3.

The sample was divided into two groups based on the presence of current suicidal ideation. Out of the possible causes, being depressed, sense of hopelessness and self perceived stigma were closely associated with suicidality. Sociodemographic variables, medical morbidity did not show any significant association.

This study was limited by its cross sectional design, patients characters, sample size, lack of data regarding coping skills, life events and awareness about HIV illness.

In conclusion patients who are depressed, hopeless and stigmatized by the HIV status are at greater risk of suicidal behaviour. There is high prevalence of suicidality among HIV positive patients. It is important to find out the risky patients and facilitate them for psychiatric treatment.

Remedical measures which could help to reduce this morbidity would include proper diagnosis and treatment of psychiatric disorders, teaching coping skills to alleviate the feelings of hopelessness \& measures for reducing the stigmatizing nature of HIV infection should be integrated with HIV / AIDS management.

\section{CONCLUSION:}

1. There is a strong association between suicidality and presence of Psychiatric morbidity especially Depression.

2. Adjustment Disorder has been the most common Psychiatric diagnosis among HIV positive individuals followed by Depressive Disorder.

3. Suicidal ideation is 5 times more common in patients with current Psychiatric diagnosis comparing to those without current Psychiatric diagnosis.

4. There is a strong correlation between suicidality and presence of hopelessness.

5. Alcohol has been the main substance of abuse among HIV positive individuals in our context.

6. There is no difference between those with suicidal ideation and those without suicidal ideation regarding socioeconomic variables.

7. All the individuals with suicidal ideation agree / strongly agree the stigmatizing nature of HIV illness.

8. There is a strong correlation between suicidality and self perceived stigma about HIV illness.

9. There is a no correlation between suicidality and medical morbidity.

10. There is a no correlation between suicidality and family history of Psychiatric diagnosis or suicide. 
11. There is a no correlation between suicidality and past history of Psychiatric diagnosis or suicidal attempt.

\section{LIMITATIONS:}

1. As the sample was drawn from patients attending a tertiary care hospital, the findings can't be generalized to the community.

2. Casual modeling of suicidality in HIV positive patients could have been assessed if a prospective study design was used. It was not done because of paucity of time.

3. Completed suicides couldn't be assessed, which might have altered the results if included.

4. Other factors like life events, coping skills, awareness about HIV / AIDS, utility of health services were not assessed.

5. Patients with severe mental / physical illness were not included in this study, which might have influenced the results if included.

6. Assessment was done at a single time on HIV positive individuals who gave consent for this study.

7. HIV positive patients prior to initiation of antiretroviral therapy were studied, who were in the earlier stages of the infection. Patients with AIDS stage of HIV infection who were on antiretroviral therapy were excluded from the study which might have influenced the results.

8. The correlation between $\mathrm{CD}_{4}$ count and suicidality was not assessed.

\section{BIBLIOGRAPHY:}

1. Jacob KS, John JK, Verghese A, et al. The fear of AIDS: psychiatric symptom or syndrome? AIDS CARE 1:35-38.

2. Atkinson JH, Grant I, Kennedy CL. Prevalence of psychiatric disorders among men infected with human immunodeficiency virus. Arch Gen Psychiatry 1988; 45: 859-864.

3. Dew MA, Ragni MV, Nimorwicz P. Infection with human immune deficiency virus and vulnerability to psychiatric distress: study of men with hemophilia. Arch Gen Psychiatry 1990, 17:737-744.

4. Martinez A, Israleski D, Walker C. Posttraumatic stress disorders in women attending human immunodeficiency virus outpatient clinics. AIDS Patient Care STDS 2002; 16 : 283-91.

5. Centers for Disease Control and Prevention. 1993 revised classification system for HIV infection and expanded surveillance case definition for AIDS among adolescents and adults . MMWR Recomm Rep. 1992 Dec 18;41(RR-17):1-19.

6. World Health Organization. WHO Case Definitions of HIV for Surveillance and Revised Clinical Staging and Immunological Classification of HIV-Related Disease In Adults and Children . 2007. Accessed March 30, 2009

7. Perry, S, Tross, S (1984). Psychiatric problems in AIDs in patients in the New york Hospital. Preliminary report. Public Health reports,99,pp. 200-205.

8. Dilley, J.W., Ochitill, H.N., Perl, M.B. et al (1985). Findings in psychiatric consulations in patients with acquired immunodeficiency syndrome. American journal of psychiatry, 142, pp. 82-86. 
9. Rundell, J, Thomason, j, Zajac, R, Beatty, D and Boswell, R (1988). Psychiatric diagnosis and attempted suicide (AS) in HIV infected USAF personnel, paper presented at the fourth international conference on AIDS (abstracts p. 407).

10. Lykestos, C.G., et al (1994). Screening for psychiatric morbidity in a medical outpatient clinic for HIV infected persons. InJ. Psych. Med., 24 (2), pp. 103-113.

11. King, M.B (1989). Psychosocial status of 192 outpatients with HIV infection and AIDS British Journal of Psychiatry, 154, pp. 223-242

12. Deshpande, S.N., Sundaram KR., Wig, N.N. (1989). Psychiatric disorders among medical inpatients in an Indian Hospital. British Journal of Psychiatry, 154, pp. 504-506.

13. Falstich, M (1987). Psychiatric aspects of AIDS. A American Journal of Psychiatry, 144, pp. 551-556.

14. Seth, R, Granville - Grossman, K, Goldmier, G. et al (991). Psychiatric illness in patients with HIV infection and AIDS. British Journal of Psychiatry, 159, pp. 347-350.

15. Maj, M, Satz, P, Janssen, R et al (1994a). Who neuropsychiatric AIDS study, Cross sectional phase I. Archives of General Psychiatry, 51, pp. 39-49.

16. Maj, M, Satz., P, Janssenm R. et al (1994 b). who neuropsychiatric AIDS study. Cross sectional phase II. Archives of General Psychiatry, 51, pp. 51-61.

17. Williams, J.B.W., Rabkin, J.G., Remein, R.H., et al (1991). Multi - disciplinary baseline assessment of homosexual men with and without human immunodeficiency virus infection. Arch. Gen Psychiatry, 48, $124-130$

18. Holt, R, Court P, Vedhara, $K$ et al (1998). The role of disclosure in coping with HIV infection. AIDS Care, 10, pp. 49-60.

19. Kelly, B.B., Raphael, A.M. et al (1998). Suicidal ideation, suicide attempts and HIV infection psychosomatics, 39, pp. 405 - 415.

20. Golding, M, \& Perkings, D.0. (1996). Personality disorder in HIV infection. International Review of Psychiatry, 8, pp. 253-258.

21. Perkins, D.O., Davidson, E. J., et al (1993). Personality disorders in patients infected with HIV. American Journal of Psychiatry, 150, pp. 309-315.

22. Catalan, J, Klimes, I, Bond, A, Day, Garrod, A and Rizza , C (1992). The psychosocial impact of HIV infection in men with haemophilia. Journal of psychosomatic research, 36, pp. 409-416.

23. Cohen MA, Alfonso CA. Psychiatric manifestations of the HIV epidemic. AIDS Reader 1994; $4: 97-106$.

24. Sherr, L (1995). Suicide and AIDS: lessons form a case note audit in London, AIDS Care, 7, psychiatry 145 , pp. 765

25. Fishman, B,m Perry, S., Jacobsberg, L. and Francis, A. (1989). Psychological factors predicting distress after HIV testing. Fifth international conference of AIDS, Montreal, Canada.

26. Chander G. Himelhoch S, Moore RD. Substance abuse and psychiatric disorders in HIV positive patients : Epidemiology and impact on antiretroviral therapy. Drugs 2006; 66: 769-89.

27. Chandra PS. Gandhi C. Satishchandra P. Kamat A, Desai A, Ravi V, et al. Quality of life in HIV subtype $C$ infection among asymptomatic subjects and its association with C4 counts and viral loads: A study from South India. Quality Life Res 2006: 15:1597 - 605

28. Miller., D, Acton, T.M.G. \& Hedge, G. (1988). The worried well their identification and management. Journal of the Royal College of physicians of London, 22, pp. 26-33. 
29. WHO (1988). Report of the consultation on the neuropsychiatry aspects of HIV infection Geneva, 14-17. March 1988. Who, Geneva,

30. Faulstich ME. Psychiatric aspects of AIDS. Am JPsychiatry 1987; 144 : 551-6.

31. Jacob KS, Eapen V, John JK. Psychiatric morbidity in HIV infected individuals. Indian J Med Res 1991; $93: 62-6$.

32. Schaerf, F.W., Koening, T. \& Wisner Carlson, B. (1989). Frequency of psychiatric disorders in hospitalized AIDS patients. Abstracts. Fifth international conference of AIDS, Montreal, Canada.

33. Namir, S, Wolcott, D.L. Fawzy, F.I. \& Alumbaugh, M.J. (1987). Coping with AIDS: psychological and health implications. Journal of applied social psychology, 17, pp. 309328.

34. Holland, J.C.\& Tross, S. (1985). The psychosocial and neuropsychiatric sequelae of the AIDS and related disorders. Annals of internal medicine, 103, pp. $760-764$.

35. Zich, J.\& Temoshok, L. (1987). Perceptions of social support in men with AIDS and ARC journal of Applied Social Psychology, 17, pp. 193-215

36. Lykestos, C.G., Hoover, D. R., Dew, M.A., et al (1996). Changes in depressive symptoms as AIDS develops. The multicentre AIDS Cohart Study. American Journal of Psychiatry, 153, pp. $1430-1437$

37. Brown, G.R and Rundell,J.R (193). A prospective study of psychiatric aspects of early HIV disease in women. General Hospital Psychiatry,15,pp.139-147.

38. Chandra PS, Ravi V, Desai A. Anxiety and depression among HIV-infected heterosexualsA report from Indian.J Psychosom Res 1998; 45 : 401-9.

39. Chandra PS. Psychosocial and sexual adjustment among persons living with HIV. National Institute of Mental Health and Neurosciences, Bangalore; 2002 p. 56-8.

40. Krishna VAS, Chandra PS. Concerns and psychiatric morbidity among people living with HIV/AIDS. NIMHANS J 1998; ?? : 253-60.

41. Hintz S, Kuck J, Peterkin J, et al. Depression in the context of human immunodeficiency virus infection: Implications for treatment. J Clin Psychiatry 1990, 51: 497-501.

42. Rabkin,J.G.,Ferrando,S.J.,et al(1997).Prevalence of Axis I disorder in an AIDS Cohort:a cross sectional,controlled study. Comprehensive Psychiatry,38,pp.146-154.

43. Jeffrey Ciesla, M.A., \& Joh \& Roberts (2001). Metaanalysis of the relationship between HIV infection and Risk for depressive disorders. American journal of psychiatry, 158, pp. 725-730.

44. Wig N, Sakhuja A, Agarwal SK, Khakha DC, Mehta S. Vajpayee M. Multidimensional helath status of HIV - infected outpatients at a tertiary care center in north India. India J Med Sci 2008:62:87 - 97.

45. Bannerjee S. Arya RK. Depression as the first symptom in AIDS patients. India J Psychiatry 1992; 34:55- 6.

46. Chandra PS, Krishna VA, Ravi V, Desai A, Puttaram S, HIV related admissions in a psychiatric hospital : A five year profile. India J Psychiatry 1999; 41:320-4.

47. Johannessen DJ, Wilson LG, Mania with crytococcal meningitis in two AIDS patients. J Clin Psychiatry 1988; 49: 20-210.

48. Maxwell S, Scheftner WA, Kessler HA, et al. Manic syndrome associated with zidovudine treatment, JAMA 1988; 259; 3406-3407.

49. Sabhesan S, Edwin T, Nammalvar N, Nageswari A. New onset Psychosis in AIDS. Indian J Psychiatry 1998; $40: 383-5$. 
50. Venugopal D, Patil PB, Gupta D. Murali N. Kar N, Sharma PS. Mania in HIV infection . India J. Psychiatry 2001: 43- 242- 5

51. Ramsubramanian C, Balaji Kumar VV. Kuamr GS. Chinnian RR, Kannan M, et al. Prevalence of post traumatic stress disorder among persons living with HIV/Aids (PLWHA). 59th Annual National Conference of Indian psychiatric society. Chennai : Indian Journal of psychiatry 2007

52. Madan PC, Singh N, Golecha GR, Sociodemographic profile and psychiatric morbidity in HIV seropositive defence personnel. India J Psychiatry 1997; 39: 20-204.

53. Brown GR, Rundell JR, Mcmamis SE, et al. Prevalence of psychiatric disorder in early stages of HIV infection. Psychosom Med 1992; 54:588-601.

54. Rundell, J.R., Brown, G.R (1992). Persistence of psychiatric symptoms in HIV seropositive person (letter). American Journal of Psychiatry, 147, pp. 674-675

55. Harris MJ, Jeste DV,Gleghorn A, Sewell DD. New-onset psychosis in HIV infected patients. J Clin Psychiatry 1991; 52:369-76.

56. Alciati A, Fusi A, D`Arminio Monforte A, Coen M, Ferri A, Mellado C. New - onset of delusions and hallucinations in patients infected with HIV. J Psychiatry Neurosci 2001; 26:229 - 34 .

57. Price, R.E., Brew, B., Siditis, J, et al (1988). The brain and AIDS: Central Nervous system HIV - I infection and AIDS dementia complex. Science, 239, pp.586-591.

58. Heaton RK, Marcotte TD, Mindt MR, Sadek J, Moore DJ, Bentley H, et al. The impact of HIV-associated neuropsychological impairment on everyday functioning $J$ Int Neuropsychol Soc 2004; 10 : 317-31

59. Satishchandra P, Nalini A, Gourie-Devi M, Khanna N, Santosh V, Ravi V, et al. Profile of neurologic disorders associated with HIV/AIDS from Bangalore, south India (1989-96). Indian J Med Res 2000; 111 : 14-23. 39. Ranga U, Siddappa B, Ramakrishna L, Nage

60. Aylward EH, Henderer JD. McArthur JC, et al. Reduced basal ganglia volume in HIV - 1 associated dementia: results from quantitative neuroimaging. Neurology 1993; 43 2099-2104.

61. Navia BA, Cho E-S, Petito CK, et al. the AIDS dementia complex: II, Neuropathology. Ann Neurol 1986; 19:525 - 535.

62. Newman SP, Lunn S, Harrison MJG.Do asymptomatic HIV seropositive individuals show cognitive deficit?AIDS 1995; 9; 1211 - 1220.

63. Mirante E. Drug injecting in Manipur, India. The Burma connection. AIDS Soc 1993; 4 : 4.

64. Desai NG. Injection drug use: harbinger of HIV/AIDS. Health Millions 1997; 23 : 10-20.

65. Kumar MS, Mudaliar S, Thyagrajan SP, Kumar S, Selvanyagam A, Daniel D. Rapid assessment and response to injecting drug use in Madras, South India. Int J Drug Policy 2000; $11: 83-98$.

66. Rapport, M. \& Braff, D.L. (1988). AIDS and homosexual panic. American journal of psychiatry 142, pp. 1516.

67. Miller, F, Wesden, P, Sacks, M \& Woznia, J (1986). Two cases of factitious acquired immune deficiency syndrome. American Journal of Psychiatry, 143, 1483

68. Marzuck P, Tierney $\mathrm{H}$, Tardiff $\mathrm{K}$, et al. Increased risk of suicide in persons with AIDS. JAMA 1988; 259: 1333-1337.

69. Linehan,M (1986). Suicidal people: one population or two?, Annals of the New york Academy of Science,487,pp.16-33. 
70. Rabkin,J.G.,Remien,R, Katoff,L and Williams, J.B.W.(1993). Suicidality in AIDS longterm survivors : what is the evidence? .,AIDS Care,5,4, pp.401-412.

71. Carrico AW, Johnson MO, Morin SF, Remien RH, Charlebois ED, Steward WT, Chesney. Correlates of suicidal ideation among HIV-positive persons. AIDS. 2007 May 31;21(9):1199-203

72. Robertson K, Parsons TD, Van Der Horst C, Hall C .Thoughts of death and suicidal ideation in nonpsychiatric human immunodeficiencyvirus seropositive individuals. AIDS Neurological Center,

73. The prevalence of suicidal behaviours in a group of HIV-positive men. AIDS Care. 2006 Aug;18(6):574-6

74. Judd FK, Mijch AM. D expressive symptoms in patients with HIV infection .Aust N Z J Psychiatry. 1996 Feb;30(1):104-9.

75. Kalichman SC, Heckman T, Kochman A, Sikkema K, Bergholte J. Depression and thoughts of suicide among middle-aged and older persons living with HIVAIDS.Psychiatric Serv. 2000 Jul;51(7):903-7.

76. Cooperman NA, Simoni JM. Suicidal ideation and attempted suicide among women living with HIV/AIDS.J Behav Med. 2005 Apr;28(2):149-56.

77. Caroline Cassel Suicide Rate Declines in HIV-Positive Patients, But Remains High January 25, 2010 -Am J.Psy. 2010;166:1-87;117-9

78. Santhosh P. Clinical predictors of suicidal ideation in HIV seropositive population. MD thesis. Bangalore :National Institute of Mental Health and Neuro-sciences;2004.

79. Chochinov H.M., Wilson, K.G. et al (1995). Desire for death in the terminally ill. Am JI. Of psychiatry, 152, pp.1185 - 1191.

80. Beck,A.T.,Kovacs,M and Weissman, A (1975). Hopelessness and suicidal behaviour. Journal of the American Medical Association,234,pp.861-865.

81. Gala, C, Pergami, A, Catalan, J, Riccio, M, Durbano, G, Musicco, M, Baldeweg, T and Invemizzi, G (1992). Risk of deliberate self harm and factors associated with suicidal behaviour among asymptomatic individuals with human immunodeficiency virus infection, Acta Psychitrica Scandinavia, 86, 1, pp. 70-75.

82. Catalan, J, Seijas, D, Lief, T, Pergami, A and Burgess, A (1995). Suicidal behaviour in HIV infection. A case control study of deliberated self harm in people with HIV infection, Archives of Suicide Research, 1, pp, 85 - 96.

83. Dannenberg, A.L., McNeil, J.G., Brundage, J.F. and Brookmeyer, R. (1996). Suicide and HIV infection: mortality follow up of 4147 HIV seropositive military service applicants, JAMA, 276, pp. 1743-1746.

84. Bellini M, Bruschi C. HIV infection and suicidality. J Affect Dis 1996; 38: 152-164.

85. Morin, S. F., K. A \& Malyon, A. K. (1984). The psychological impact of AIDS on gay men. American psychologist, 39, 1288-1293.

86. Kelly, B., Raphael, B., Judd, R, et al (1998). Psychiatric disorders in HIV infection. Australian newzealand journal of psychiatry, 32, pp. $441-453$

87. Michael Carter .One-in-five HIV-positive individuals thought of suicide in past week, finds US study Published: 16 May 2007.

88. Ahuja AS, Parkar Sr, Yeolekar Me, Psychosocial aspects of seropositive HIV patients. J Assoc Physicians India 1998; 46: 277-80

89. Gala, C, Pergami, A, Catalan, J, Riccio, M, Durbano, F, Musicco, M, Baldeweg, T and Invernizzi, G(1992).Risk of deliberate self harm and factors associated with suicidal 
behaviour among asymptomatic individuals with human immunodeficiency virus infection, Acta Psychitrica Scandinavia, 8, 1pp.70-75.

90. Perkins DO, Stein RA, Golden RN, Murphy C, Naftolowitz D, Evans DL, Mood disorders in HIV infection. Prevalence and risk factors in a non epicenter of the AIDS Epidemic. Am J Psychiatry 1994; 15 : 233-6.

91. Miller, R (1995). Suicide and AIDS: problem identification during counseling, AIDS Care, 7, suppl 2, pp. 199-205

92. American Academy of Neurology. Nomenclature and research case definitions for neurologic manifestations of human immune deficiency virus - type 1 (HIV -1) infection. Neurology 1991; 41: 778 - 785.

93. Pergami A, Gala C, Burgers A, et al. Heterosexuals and HIV disease: A controlled investigation into the psychosocial factors associated with psychiatric morbidity. J Psychosom Res 1994; 38: 305-313.

94. Starace F. Suicidal behaviour in people infected with human immunodeficiency virus: A literature review. Int J Soc Psychiatry 1993; 39: 64-70.

95. Bing,2001;Arch.General and psychiatry 58:721-8

96. Martinez, 2002, AIDS patient care, STDS 16; 283-91

97. Kuupmen 2002, Int.J.Psychiatry med.32:361-78.

98. Kumar et al, Kuppuswamy's socio economic status scale-updating for 2007. Indian journal of paediatrics December 2007 vol:74; number 12.

99. Hamilton M- A rating scale for Depression. J Neurol. Neurosurg. psychiatry,1960;23: P56-62. 